\title{
A Sustainable Future: Strategic Planning and the Role of Technology
}

\author{
Ranil D. Guneratne
}

Former Director, National Science and Technology Commission of Sri Lanka

ABSTRACT
By the latter half of the 2Oth Century, the rapidly expanding human
population and the technology that made it possible had begun to have
consequences which raised doubts about the sustainability of the current
form of human civilization. Massive dependence on fossil fuels has not only
depleted our sources of petroleum, but also significantly increased carbon
dioxide concentrations in the atmosphere, resulting in increased global
temperatures and changes in climate. The spread of human settlements
has also resulted in deforestation and a drastic reduction in biodiversity,
which is leading to a new mass extinction. Other non-renewable natural
resources are also being used up. In the long term, it seems likely that the
Earth will recover from these effects, but in the short to medium term, the
very survival of the human species cannot be guaranteed.
To sustain the current and projected human population at an acceptable
level of comfort, security, and lifestyle requires careful, coordinated
planning and technological solutions to the problems created by
technology itself. These will include increased use of renewable sources
of energy, sustainable high-tech agriculture and food production, and
the widespread use of new medical and biotechnologies. The effects of
the coming so-called 4th Industrial Revolution, spearheaded by artificial
intelligence, must be taken into consideration. While this is expected to
increase productivity and expand the economy, it will also have major
social consequences which should be planned for ahead of time. These
technologies will raise unprecedented ethical and legal issues, which
should also be addressed in the planning process.

\section{KEYWORDS:}

Technology, agriculture, renewable energy, demographics, 4th Industrial Revolution

Suggested Citation: Guneratne R. D. (2021). A Sustainable Future: Strategic Planning and the Role of Technology. University of Colombo Review (New Series III), 2(2), 107 - 121.

(C) 2021 The Authors. This work is licenced under a Creative Commons Attribution 4.0 International Licence which permits unrestricted use, distribution, and reproduction in any medium, provided the original work is properly cited. 


\section{Introduction}

In the 1970's, a British scientist named James Lovelock first put forward the hypothesis that the Earth behaves like a living organism, with the ability to maintain its environment, including conditions suited for Life on its surface (Lovelock, 1979). He postulated that the Earth had built-in mechanisms to correct large perturbations in those conditions, and that the biosphere itself played a major part in those mechanisms. Several other scientists, notably Lynn Margulis, contributed to this idea, which became known as the Gaia hypothesis, after the Greek goddess of the Earth (Lovelock \& Margulis, 1974).

In part because of its metaphor of the Earth as a living organism, in part because of the mythical connotations of its name, but also in part because of the prevailing orthodoxy that the biosphere, the totality of organisms living on the surface of the planet, responds to its environment rather than vice versa, most scientists did not accept the Gaia hypothesis. At the very least, however, it has provided them with food for thought, an alternative way of looking at things, and it has been a subject for intense discussion and debate. As evidence accumulated, it has become increasingly more mainstream. While it may have attracted some New Age supporters in its day, today it is very much a scientifically accepted theory.

An interesting aspect of the Gaia hypothesis is the apparent ability of the Earth, taken as a whole and acting through its biosphere, to regulate the average global surface temperature within a certain range, and to control the composition of the atmosphere. Both geological and fossil records show that this is the case. During the last 3.5 billion years or so, since shortly after life began on Earth, the surface of the planet has suffered numerous catastrophic events resulting in mass extinctions, periods of high average global temperatures during which sea levels rose (as they have begun to now), and ice ages, when the opposite happened. But never did life completely die out, though species became extinct and were replaced in their evolutionary niches by new species. Mass extinctions, some of them due to sudden, extra-terrestrial causes like collisions with meteors, were followed by the rapid evolution of new species. In the aftermath of the evolution of photosynthesis, which resulted in oxygen becoming a major component of the atmosphere, the composition of the major gases in the atmosphere (nitrogen, oxygen, argon) changed hardly at all. Temperatures fluctuated, but never to a point where Life as a whole was threatened.

We are now at the beginning of what appears to be another mass extinction, this time with human beings as the cause. The massive increase in the human population during the last few hundred years has resulted in the encroachment of humans into the living spaces of other animals, many of whom were either slaughtered or driven to extinction by being deprived of food and territory. This is accompanied by an increase in greenhouse gases in the atmosphere, including the ever-present carbon dioxide and methane, and some anthropogenic gases, such as most halocarbons, which have never been seen before. Global temperatures have begun to rise as a result. So have sea levels. So great has been the human influence on the biosphere and atmosphere of the planet that some scientists have dubbed this period the Anthropocene Epoch (this term has not yet been formally recognized, however, so we are technically still in the Holocene Epoch). 


\section{The Consequences of Climate Change}

What are the consequences of climate change induced by human activities? If the Gaia hypothesis is true, the Earth will not be particularly affected on an epochal time scale (Joseph, 1990). Plants will respond to warmer temperatures and increased levels of $\mathrm{CO}_{2}$ in the atmosphere by growing faster and processing $\mathrm{CO}_{2}$ on a larger scale. A type of plant called $\mathrm{C} 4$, which uses $\mathrm{CO}_{2}$ more efficiently that the more common $\mathrm{C} 3$ plants, will proliferate. Methane and other greenhouse gases will be eventually removed by reacting with atmospheric oxygen. As $\mathrm{CO}_{2}$ and other greenhouse gases are removed from the atmosphere, global temperatures will go down again. New species will evolve to replace the ones driven to extinction by humans. In short, those who worry about the fate of the Earth itself need not worry.

The problem with the above scenario is that the Gaia hypothesis says nothing about the fate of any individual species. There is no guarantee that the species Homo sapiens will survive. The planet's corrective measures, as described above, happen on a very long timescale. In the short term, climate change and environmental degradation alone can bring about reduced agricultural productivity in many parts of the world, faster depletion of natural resources, mass migrations, social unrest, new diseases, and the threat of largescale famine and warfare. The worst-case scenario, from the human point of view, is that we ourselves will become part of the mass extinction that we have initiated. Short of that, death and suffering on a large scale seem probable outcomes if we cannot put in place our own, relatively short term, corrective measures.

In his remarkable book Collapse, Jared Diamond has recorded the ability of even primitive, isolated human societies to exhaust their natural resources by over-exploitation, and then die out (Diamond, 2005). His examples range from remote Pacific islanders to the first Norse settlers on the southern tip of Greenland. Interestingly, he also describes the ability of properly organized and well-led human societies to reverse over-exploitation. For example, under the Tokugawa Shoguns, 17th Century Japan was able to abruptly halt, and then reverse the massive deforestation of the country. Today, Japan, still one of the most densely populated countries in Asia, has about $70 \%$ forest cover, far more than Sri Lanka.

The global human society is an isolated one. If we exhaust our natural resources, there is nowhere else we can go, and extra-terrestrial resources are still out of reach. It is the nature of organisms to maximize their use of available resources, and history has shown that humans, under certain circumstances, can take this instinct to extremes. Conservation requires careful planning and broad (and perhaps coerced) cooperation. But history has also shown that humans are capable of both of those as well.

\section{Technology and Development}

In order to plan for the future, we must first understand the past. How did humanity achieve its current status, a tightly interconnected, global economy which supports a population of nearly 7.8 billion people, most of whom have reasonable access to adequate food, basic shelter, and clothing, if not always the levels of healthcare that even we in Sri Lanka, a relatively poor country, have come to expect? True, there are hundreds of millions 
of people who still live on the margins, but a few generations ago, it would have been unthinkable that the human population would have reached its present size without being overtaken by some sort of Malthusian catastrophe.

An enlightening summary of the human journey has been provided by Yuval Harari in his eye-opening book, Sapiens: A Brief History of Humankind (Harari, 2014). Harari lists many factors which contributed to the expansion and broad unification of the human species across the globe. However, the important one for our purposes, the one that has been responsible for our current dominance as a species and our ability to maintain a huge and still growing population, is also the obvious one: Science and sciencebased technology. Technology at this level is the outcome of about 500 years of scientific research, beginning in Europe during the late Renaissance, and is qualitatively different from empirical technologies developed throughout human history by trial and error. I do not mean to imply (as some still do) that science is a purely European construct; clearly scientific research in Europe had its roots in the science and mathematics of ancient Greece and India, and of the medieval Arabs and Persians. But it was in Europe that science and its ensuing technological outcomes became an organized activity supported by society for its own benefit.

Today, science is a global activity, and nations that have invested heavily in it have forged ahead. This includes relative newcomers, such as South Korea and Israel, which are the world leaders in investment in scientific research and development (gross expenditure on research and development, or GERD) as a percentage of gross domestic product (GDP). Table 1, below, prepared with data available from UNESCO, gives an interesting picture of the commitment of selected countries to enhancing technological progress (UNESCO Institute of Statistics, 2021).

Table 1

GERD as \% of GDP

\begin{tabular}{|l|c|c|}
\hline \multicolumn{1}{|c|}{ Nation } & Year* & GERD (\% of GDP) \\
\hline Brazil & 2018 & 1.16 \\
\hline Canada & 2018 & 1.56 \\
\hline China & 2018 & 2.14 \\
\hline France & 2018 & 2.19 \\
\hline Germany & 2018 & 3.13 \\
\hline India & 2018 & 0.65 \\
\hline Indonesia & 2018 & 0.23 \\
\hline Israel & 2018 & 4.94 \\
\hline Iran & 2017 & 0.83 \\
\hline Italy & 2018 & 1.39 \\
\hline Japan & 2018 & 3.28 \\
\hline Malaysia & 2018 & 1.04 \\
\hline Pakistan & 2017 & 0.24 \\
\hline
\end{tabular}




\begin{tabular}{|l|c|c|}
\hline \multicolumn{1}{|c|}{ Nation } & Year* & GERD (\% of GDP) \\
\hline Philippines & 2015 & 0.16 \\
\hline Russia & 2018 & 0.98 \\
\hline Singapore & 2017 & 1.92 \\
\hline South Africa & 2017 & 0.83 \\
\hline South Korea & 2018 & 4.53 \\
\hline Thailand & 2017 & 1.00 \\
\hline U.K. & 2018 & 1.70 \\
\hline U.S.A. & 2018 & 2.83 \\
\hline Sri Lanka & 2017 & 0.13 \\
\hline Vietnam & 2017 & 0.53 \\
\hline
\end{tabular}

*Latest for which data is available.

Table 1 allows a comparison between established "developed" nations, now including Israel and S. Korea, and nations aspiring to that status, including Sri Lanka. The progress made by countries such as Malaysia, Thailand, South Africa, Brazil, and even Vietnam, which have invested significantly in research and development (R\&D), stands in sharp contrast to Sri Lanka, whose record in such investment has been historically poor.

\section{Technology in Agriculture and Healthcare}

While most people think of science and technology (S\&T) in industrial and manufacturing terms, it is very important to remember its critical contribution to two other fields: healthcare and agriculture. The impact of science and technology on agriculture and food production affects all aspects of these activities: genetics and plant breeding, soil science and fertilizers, pesticides, mechanization and automation, biotechnology, postharvest processing, etc. The result has been a large and sustained increase in global food production, by a factor of more than 3 since 1960, significantly outpacing the corresponding increase in population.

South Korea is an interesting example of accelerated development, though one that would be difficult for most other countries to emulate. In 1960, it was one of the poorest countries in the world. Agriculture and fisheries contributed 63\% to its GDP, a figure indicative of subsistence agriculture. By 2008, this sector comprised only $8 \%$ of GDP, typical of an industrialized nation (Sung, 2010), and today it is under $2 \%$ of GDP, comparable to the U.S.A. (World Bank, n.d.). During this period, however, actual agricultural production in South Korea increased fourfold, whereas the population only doubled. In Sri Lanka, agriculture accounts for a little over 7\% of GDP, suggestive of an industrialized country; however, the fact that over $25 \%$ of the workforce still depends on agriculture (Central Bank of Sri Lanka, 2020) allows us to maintain the myth that Sri Lanka is primarily an agricultural nation. This statistic is somewhat disturbing, as it indicates a lack of productivity and suitable technology in the agricultural sector, and a corresponding depth of rural poverty. Add the fact that our manufacturing industry, taken as a whole, is 
at the bottom of the value addition chain, a consequence of decades of poor investment in $\mathrm{R} \& \mathrm{D}$, and it is hardly surprising that Sri Lanka has only recently been classified as a lower middle-income country.

The improvements in medicine and healthcare since the Second World War led to a dramatic decline in infant mortality and a steady increase in life expectancy worldwide. Fertility rates did not start falling until much later, mostly due to improvements in female education and literacy, and the entry of more women into the workforce. Between 1960 and the present time, the world's population increased by a factor of more than 2.5 , and the rate of increase has only recently begun to slow down. The technology driven increases in agricultural output, the continuous improvement and innovation in healthcare, and the numerous other contributions of scientific research and technology to industrial and economic growth have all contributed to maintaining and feeding this population, and even to meeting the aspirations of the burgeoning middle classes in every country. However, this has come at a certain cost.

\section{Technology and the Environment}

The scientists that developed these technologies, and the corporations that commercialized them, were initially oblivious to the consequences to the environment - soil, atmosphere, rivers and lakes, even oceans, and, of course, wildlife. In parts of the U.S.A., soils were contaminated by high concentrations of arsenic from added herbicides (Yang \& Donahoe, 2007). Seafood caught in Minamata Bay in Japan was found to have high levels of mercury (Minamata disease, 2021). Polychlorinated and polybrominated hydrocarbons were found to be all but indestructible in the environment. Meanwhile the atmosphere was affected by multiple issues: acid rain downwind of coal-burning power plants, photochemical smog in crowded cities, destruction of the ozone layer in the stratosphere by chlorofluorocarbons (CFCs), and the accumulation in the atmosphere of greenhouse gases such as $\mathrm{CO}_{2}$ and methane, which has led to what is now called climate change. Industrial accidents, some of them lethal, played their role: Seveso, Bhopal, Chernobyl, etc.

Evidence accumulated, and the issues could no longer be ignored. Rachel Carson's famous book Silent Spring woke people up to the danger of the insecticide dichlorodiphenyltrichloroethane (DDT) persisting in the environment (Carson, 1962), even though it had all but eradicated malaria, thereby saving millions of lives. Rowland and Molina eventually received the Nobel Prize in Chemistry for their work on the destruction of ozone by CFCs (Molina \& Rowland, 1974), and the Montreal protocol of 1995, one of the most successful international agreements on the environment, set a timetable to eventually ban their use, even though they were perfect in every other way as refrigerants, solvents, and aerosol propellants - completely inert and non-toxic. DDT was replaced by other insecticides - perhaps less effective, but biodegradable; CFCs were likewise replaced by hydrofluorocarbons, which slowly oxidize in the presence of atmospheric oxygen.

These two examples illustrate a point I wish to make. Environmental problems are caused by technology which is developed in response to a perceived societal need, compounded by the sheer scale of the human population. Technology, however, is a genie which cannot be put back in its bottle. The solution to the problem is not to go back to a past 
which is no longer viable (given both the intervening population increase and the greater aspirations of people), but to a future with newer and better technology, which has been developed taking into consideration the deficiencies of the old.

The most powerful instance of this is our energy consumption. There was a time when the progress of human civilization could be measured by total energy consumption. We went from human muscles to animal muscles with some wind power thrown in, and then to an increasing and, eventually, near total dependence on fossil fuels over the past 200 years (with some nuclear power thrown in for good measure during the latter third of this period). We then discovered, by the 1990s, that two major issues had arisen: (i) the release of huge amounts of $\mathrm{CO}_{2}$ into the atmosphere was causing the planet's surface to heat up, and (ii) sources of petroleum, the most popular form of fossil fuel, was being depleted quite fast, while coal, even more polluting, was also running out, though more slowly. The pressure to reduce the consumption of petroleum and the expectation that oil prices would skyrocket as oil wells dried up forced states and corporations to invest large amounts of money to research alternatives, with the following results.

- Countries continued to invest in, or, like Sri Lanka, show an interest in, nuclear fission energy, partly for military reasons, but this is a dangerous technology plagued by many problems, including the disposal of radioactive waste and the possibility of devastating accidents like the ones at Chernobyl and Fukushima.

- Vast amounts of money were spent on research into nuclear fusion energy, but the breakthroughs needed for commercialization were never achieved.

- Biofuels, particularly bio-diesel and ethanol, showed some promise of commercial viability, depending on oil prices at any given time. However, this could become a major alternative in most countries only at the expense of food production. The only country that went into bio-ethanol in a major way was Brazil, and the cost to the Amazon rain forest was high. Of course, firewood, charcoal, etc., have always been and continue to be an important source of energy for domestic cooking and, in cold climates, heating.

- Hydropower has been in use for a long time, in the form of huge dams with turbines for electricity generation. However, these mega projects were not without environmental consequences, and the world's rivers can only accommodate so many dams. So-called mini-hydro power plants remain an alternative for small-scale local power generation.

- The other important sources of renewable energy were wind power and solar power. For a long time, these were considered niche sources - expensive and low capacity, but with the advantages of being very clean and requiring little maintenance once set up. During the last decade or so, these technologies have emerged as the winners. Research has produced photovoltaic materials with greatly improved efficiency and batteries with greater storage capacity, while mass production has reduced cost. Wind and solar power are already competitive with fossil fuels in terms of price, and are expected to become cheaper in the near future; they already are in many countries.

Coupled to the development of alternative sources of power generation, another important trend has reduced our dependence on fossil fuels, viz., improved efficiency. 
The idea that less might be better has finally taken hold. Manufacturers are now focused on designing energy-efficient products, from light bulbs to cellphones to vehicles. The electrification of cars is one of the most significant trends of the past decade, and some European countries plan to allow only completely electric cars to be sold by 2030, signaling the end of our love affair with the internal combustion engine. Improved storage devices, mostly based on lithium-ion batteries, have played a pivotal role in this. The rapid spread of these technologies has already resulted in a significant drop in the global demand for petroleum. Oil prices peaked just before the global financial crisis of 2008 and have never reached those dizzying heights again (Macrotrends, 2021).

When preparing for the future, we can expect the rapid development of advanced technologies, many of which will provide solutions to present or anticipated problems, while others, if not properly thought through, may have unforeseen consequences, either environmental or social. Technologies to minimize and recycle waste must necessarily be an important component of a sustainable economy. In such a system, known as a circular economy, products at the end of their life should become inputs into new processes.

For many people, a sustainable future is a static one, in which technological progress has been frozen or even reversed. It has become fashionable, both in the West and the East, for segments of society to denigrate science or reject its conclusions, sometimes in the name of religion or some conservative ideology (as in parts of the U.S.A.), sometimes because of a cultural nostalgia for an ancient or even mythical past (as in parts of South Asia). But we cannot return to the past, and we cannot even stand still. The technology and agriculture that (barely) supported 10 million people in Sri Lanka in 1960 will not support 22 million in 2022. The future will be dynamic. Whether it is sustainable would be up to us. What is needed is (i) a good sense of the technological and demographic trends for at least the next 50 years, (ii) selection of current and anticipated technologies to promote, based on environmental as well as economic considerations, (iii) planning how to exploit and conserve non-renewable natural resources in the face of advancing technology, and (iv) preparation for the inevitable social, legal, regulatory, and ethical considerations that accompany new technologies.

\section{Planning for the Future: The Fourth Industrial Revolution}

Since the so-called First Industrial Revolution (the discovery of the steam engine and its applications), the goal of much of humanity has been the ever-accelerating pursuit of wealth and a comfortable, often profligate, lifestyle. Successive industrial revolutions (the Second initiated by the internal combustion engine and electrification, the Third by computer and information technology) each contributed to a dramatic expansion in human productivity, use of natural resources, and scientific and technological advances, supporting a rapidly increasing human population. The global population reached approximately one billion at around 1830, and two billion a century later. Almost another century has passed, and nearly 8 billion human beings roam the planet. All of them need to be fed, sheltered, and clothed, and increasing numbers strive to achieve a lifestyle once associated with the wealthy and powerful. This has had predictable consequences on the environment and the availability of natural resources. 
Humanity is now at the start of yet another industrial revolution, the Fourth (dubbed 4IR). The distinguishing technology of this one is artificial intelligence (AI), though rapid advances in biotechnology, information technology, engineering (including robotics or mechatronics), and material science all play a role. 4IR will also undoubtedly lead to enormous increases in human productivity and the use of resources (World Economic Forum, 2021). However, although many economists as well as technologists have been unwilling to admit this, there are indications that 4IR will be qualitatively different from its predecessors.

Each industrial revolution led to increased mechanization and automation, and the threat of massive job losses. Some types of jobs certainly were lost, but overall, this was compensated for by the creation of new jobs. In developed countries, as well as rapidly industrializing ones, the burgeoning service and manufacturing industries were able to absorb the excess labor no longer needed by an increasingly efficient agricultural sector. Many countries, from post-World War Two Germany to present day Malaysia, and much of the Middle East, became importers of labor. Even Sri Lanka is showing some signs of this.

However, this trend is likely to be reversed by 4IR. The synthesis of robotics with artificial intelligence means that any job that requires routine, repetitive operations can be done more efficiently and eventually more cheaply by a machine. We already have selfdriving cars. It is only a matter of time before this trend extends to all sectors of transport. Buses, taxis, trains, ships, and aircraft will all drive, sail, or fly themselves with minimal, possibly remote, human supervision. Parcel deliveries will be handled by drones, a technology that is already available. Millions of human jobs will be lost in this automated transport sector, from taxi and bus drivers to traffic police. New jobs will be created to maintain these automated systems, but these will be far fewer, as routine maintenance would also be automated. Not too long ago, all this would have been considered science fiction. Today it is fast becoming a reality.

A small American company called AppHarvest illustrates what might become the future of agriculture (AppHarvest, 2021). Its crops are grown in a controlled environment in vast greenhouses in the Appalachian Mountains of Kentucky, U.S.A. Its processes use recycled rainwater to conserve water, and LED lighting as well as sunlight to extend the growing period. Integrated pest management using beneficial insects reduces the use of chemical pesticides. The crops are grown year-round, and are harvested by robots. AI plays an important role in the entire process, which is designed to maximize efficiency and reduce inputs and waste.

The manufacturing and service sectors, and even the agricultural sector will all be affected by AI and robotics. Most of these jobs are repetitive, and intelligent robots with the ability to learn (the hallmark of AI) will be able to teach themselves on the job, much like humans, rather than depend on a pre-programmed set of computer algorithms to dictate their operations. It is highly probable that the factories of the future will be fully automated, manned by robots, with a small cadre of human supervisors. Millions of relatively highly paid, skilled jobs will vanish. Much of the routine work of agriculture could likewise be easily done by robots. Nor is the service sector, which has often picked up the slack in these situations, immune. We have already discussed transport, but restaurant waiters, domestic 
servants and attendants, hospital orderlies, administrative assistants in offices, in short, anyone whose work is mostly routine and mechanical can be replaced by a robot. Even highly skilled professions would be affected. Quite a bit of the work done in the legal, medical, and teaching professions is routine and follows set procedures. Not that these professions will disappear, but a lawyer, a lecturer, or a surgeon with robotic assistance could be so much more productive that fewer such jobs will be needed. And of course, the probable automation of warfare and security operations is a terrifying prospect.

Planning for a sustainable future must take into consideration the social impact of the technologies which are now, so to speak, in the pipeline. Artificial intelligence and robotics are definitely in that pipeline. While a massive increase in productivity and overall human wealth could result, that wealth may end up very unevenly distributed. In order to avoid the potential for social unrest, a new social paradigm will have to be established to ensure that segments of humanity, including perhaps entire nations, are not left behind.

Another group of technologies which will have a major impact in the coming years are biotechnologies. Future technologies will include some, or all of the following.

- genetic medicine and personalized healthcare

- improved stem cell technologies to produce replacement organs, possibly even limbs

- cloning as an alternative for human reproduction

- tissue culture as an alternative to animal husbandry for meat production

- continued use of genetically modified organisms in agriculture, animal husbandry, and medicine

Not all these technologies are universally accepted today, to the extent that they exist, so a fair amount of public debate will have to occur as part of the process of incorporating them into plans for the future. One of the outcomes would be an increase in human longevity. In an era of aging populations in developed nations (although Sri Lanka cannot be included in this category, it is also facing the same problem), the issue of how such a population is to be supported needs to be addressed.

\section{Demographic Considerations}

This brings us to the other major issue which needs to be taken into consideration in future planning: demographics. Although the rate of growth has slowed, the global human population is still rising. It is projected to level off at about 10.8 billion people (from the current 7.8 billion) around 2100 or so (PopulationPyramid, 2019). However, there is a wide variation among different countries and regions. There is a well-known correlation between high levels of female education and employment, and low levels of fertility (children per woman). In Europe and North America, as well as Japan and Singapore, fertility has been below the so-called replacement rate of 2.1 children per woman for decades. Countries which have high levels of immigration have maintained or increased their populations, but Japan and many Eastern European countries, which do not encourage immigrants, show aging and declining populations. China's one child per woman policy was a drastic measure to control population growth, but this is now backfiring, and the country recently increased its limit from two children to three. China's population is currently projected to peak at 1.46 
billion people around 2030, then decline to around 1.06 billion by 2100 . By then, Japan will have declined from its 2009 peak of 128.5 million people to about 75 million, a loss of over 40\% (PopulationPyramid, 2019).

Although Sri Lanka is not a developed country, it has high levels of female education and shows similar trends. Sri Lanka's population is projected to peak at about 22.2 million people around 2035, then decline to about 15.3 million by 2100 . By then, the largest segment of its population would be the 60-89 age group. Figures 1 and 2 below show the current and projected population pyramids (population distribution by age and gender) for Sri Lanka (PopulationPyramid, 2019). This trend towards aging and declining populations is something that planners need to take into consideration over the long term.

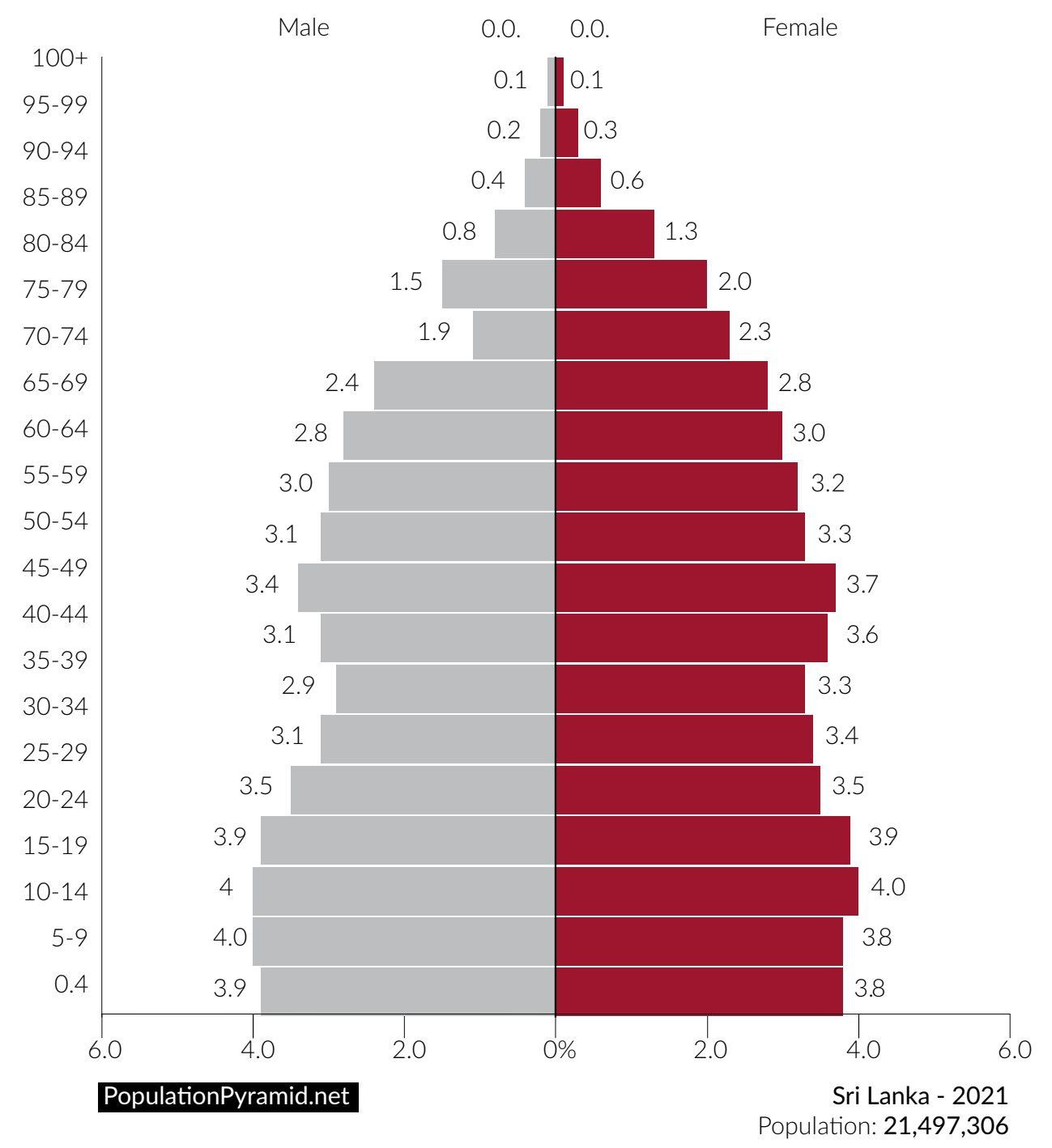

Figure 1 


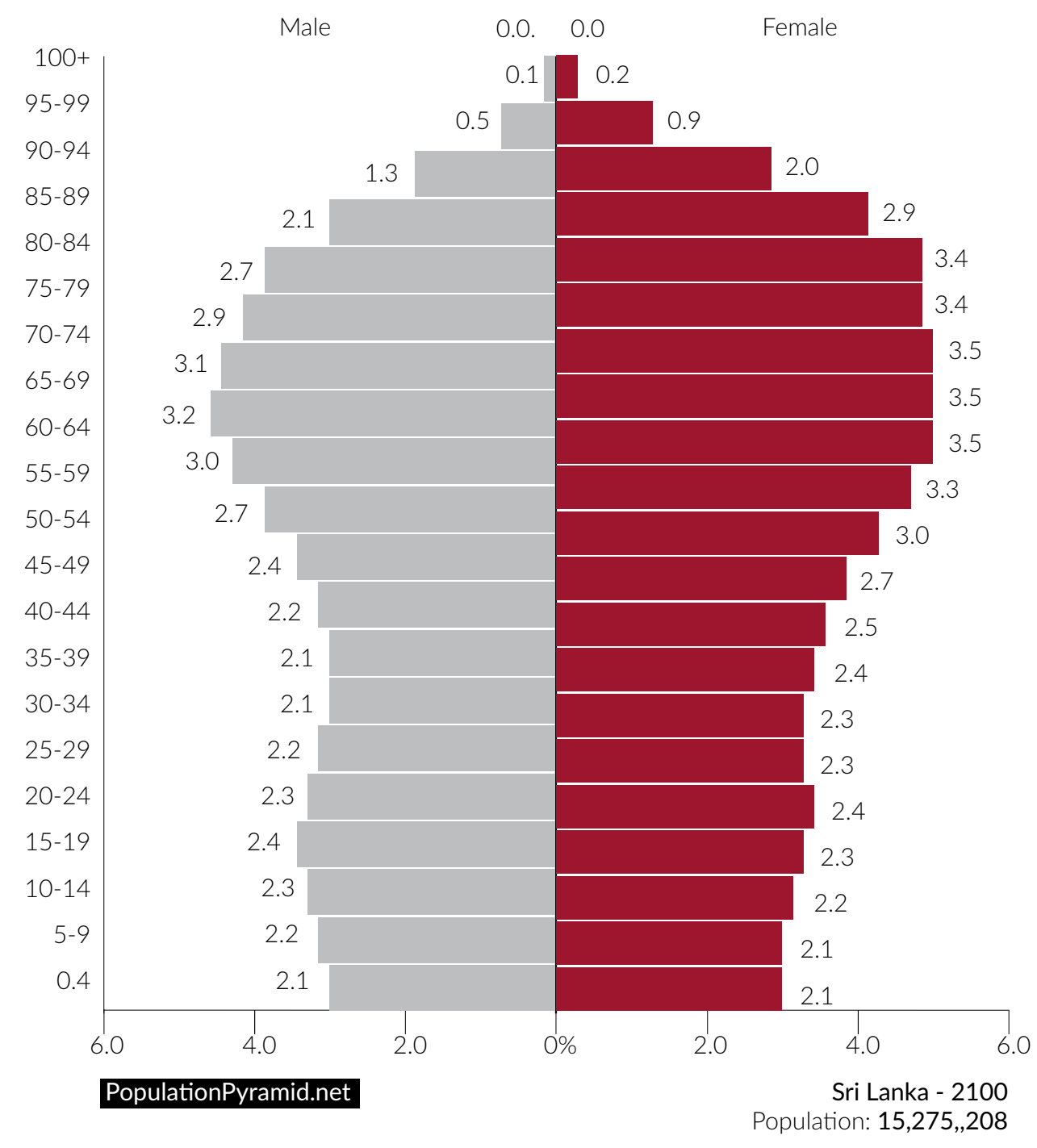

Figure 2

Population Pyramid, Sri Lanka, 2100

Of course, these numbers are projections, and any number of unexpected factors could alter them. Nevertheless, it seems probable that most countries outside Africa will have aging and declining populations in the latter half of this century and will need to factor that into their plans.

\section{Ethical and Legal Considerations}

The rapid advance of technology brings with it many ethical and legal questions, to which human societies do not have answers, since these issues are often without precedent. 
Societies take time to grapple with and reach a consensus on the rights and wrongs of issues which have never been raised before, and if necessary to convert that consensus into laws. When it comes to technological issues, the situation is made more complex by the fact that the majority of the population, even in advanced countries, have a very poor understanding of technology, let alone its implications.

While there is no international consensus, in the case of biotechnologies many countries have adopted a "better safe than sorry" approach, and limited the use of, for example, genetically modified organisms. Religious objections have also hindered progress in stem cell technologies. Countries with more liberal policies regarding these technologies have forged ahead scientifically (the U.S. was able to catch up only after Barack Obama became President and lifted the restrictions). Many technologies of the future are still in early or conceptual stages of development, including human cloning, pre-natal genetic intervention, and genetic enhancement. While most people are uncomfortable with some or all of these, there has been very little public debate about their ethics and desirability.

When it comes to artificial intelligence too, there has been very little debate regarding the ethical issues, and, perhaps because of the unprecedented nature of these technologies, there are almost no laws and policies governing them. One issue is the treatment of the artificial intelligences themselves, particularly if they were self-aware and embedded in robots, humanoid or otherwise, capable of movement, manipulation, and speech. We are now very close to producing robots which would be outwardly indistinguishable from human beings, in terms of appearance, locomotion, speech, facial expressions etc. Would such entities be ethically and legally considered to be "persons with moral status" (a concept dating back to Kant and Locke), and therefore possessing certain rights (Holland, 2017)? Or would they be considered objects, and therefore owned by others? Locke distinguished between humans and persons (Locke, 1690/2017), so the two terms are not to be considered synonymous. Would ownership of such an entity be the start of a new type of slavery? What if these robots proved stronger and smarter than humans? Would they become a threat to our continued existence?

All this sounds like science fiction, and the ethical questions posed were in fact explored in Steven Spielberg's movie AI: Artificial Intelligence in 2001. However, we are less than a generation away from it becoming reality. A prototype humanoid robot, named Sophia, has already been produced by a company in Hong Kong, Hanson Robotics, and displayed in public (Hanson Robotics, n.d.). One can watch and listen to her on YouTube. In 2017, Saudi Arabia made her an honorary citizen. While one can argue that this was a publicity stunt, it nevertheless sets a precedent.

There are many other ethical and policy issues that will arise out of these technologies during the next few decades which need to be addressed early to avoid serious social unrest. The right to make a living in the face of massive job losses, and the right to privacy, already eroded by the internet and instant telecommunications, are just two of these. We do not know how these questions will eventually be answered, but society would be unwise to leave those answers entirely up to our elected (or sometimes unelected) leaders. 


\section{Conclusions}

A sustainable future will not happen of its own accord. The competitive nature of individual humans, and their instinct to extract the most out of available natural resources, regardless of renewability, all but guarantees that. Thus, it would have to be a concerted effort, by communities, by nations, and by international cooperation.

The term "sustainable future" implies conservation - of natural resources, of biodiversity, of the environment and its climate. Thus, renewable resources should be used wherever possible, especially with reference to energy. The myth that solar and wind energy is inadequate to meet our needs has been debunked. The traditional methods of re-using and re-cycling etc., should be continued with suitable economic incentives. Manufacturing processes will need to move even further in the direction of maximizing efficiency of production, versatility and re-cyclability of products, and the re-usability of resources such as water - a concept referred to as "eco design".

Emerging and projected technologies must be carefully monitored and suitably incentivized to benefit the global community as a whole, wherever possible. Technologies that increase productivity should be encouraged but also regulated (within reason), and provision must be made for those who would be marginalized by them. Such technologies will become essential for supporting an aging population which demographic projections indicate will become a reality in the second half of this century (sooner in some countries).

Finally, a consensus will have to be reached about the ethical and legal implications of the new technologies. It seems preferable that this be done by public education and public debate.

Will humanity plan its future and work together to achieve it? Or will Nature take its course? Time will tell.

\section{References}

AppHarvest (2021). Controlled environment agriculture. Retrieved October 9, 2021. https://www. appharvest.com/agtech/

Carson, R. (1962). Silent spring. Houghton Mifflin.

Central Bank of Sri Lanka. (2020). Economic and social statistics of Sri Lanka. Retrieved July 9, 2021, from https://www.cbsl.gov.lk/sites/default/files/cbslweb_documents/statistics/otherpub/ ess_2020_e1.pdf

Diamond, J. (2005). Collapse: How societies choose to fail or succeed. Penguin Books.

Hanson Robotics. (n.d.). Sophia. Retrieved July 13, 2021, from https://www.hansonrobotics.com/ sophia/

Harari, Y. N. (2014). Sapiens: A brief history of humankind. Vintage.

Holland, S. (2017). Stem cell research and therapy. Bioethics: A philosophical introduction (pp. 15-18). Polity Press.

Joseph, L. E. (1990). Gaia: The growth of a new idea. St. Martin's Press. 
Locke, J. (1690). "Of identity and diversity". An essay concerning human understanding (Book II, eBook edition, 2017). Project Gutenberg. https://www.gutenberg.org/files/10615/10615h/10615-h.htm\#link2H_4_0008

Lovelock, J. E. (1979). Gaia: A new look at life on Earth. Oxford University Press.

Lovelock, J. E., \& Margulis, L. (1974). Atmospheric homeostasis by and for the biosphere: the Gaia hypothesis. Tellus (Series A), 26(1-2), 2-10. https://doi.org/10.1111/j.2153-3490.1974.tb01946.x

Macrotrends. (2021). Crude oil prices - 70 year historical chart. Retrieved October 9, 2021. https:// www.macrotrends.net/1369/crude-oil-price-history-chart

Minamata disease. (2021, July 13). In Wikipedia. https://en.wikipedia.org/wiki/Minamata_disease

Molina, M. J., \& Rowland, F. S. (1974). Stratospheric sink for chlorofluoromethanes: chlorine atom catalysed destruction of ozone. Nature, 249, 810-812.

PopulationPyramid. (2019, December). Population Pyramids of the World from 1950 to 2100. Retrieved October 9, 2021. https://www.populationpyramid.net

Sung, K.-J. (2010, June 28). Korea's rapid economic development: An analysis of an eye-witness [Workshop session]. Adaptation of Best Asian Innovation Practices in the Sri Lankan Context, Colombo.

UNESCO Institute of Statistics. (2021). Science, technology, and innovation. Retrieved October 9, 2021. http://data.uis.unesco.org/Index.aspx?DataSetCode=SCN_DS\&lang=en

The World Bank. (n.d.). Agriculture, forestry and fishing, value added (\% of GDP). Retrieved July 9, 2021, from https://data.worldbank.org/indicator/NV.AGR.TOTL.ZS? locations=KR

World Economic Forum. (2021). Centre for the Fourth Industrial Revolution, Retrieved October 9, 2021. https://www.weforum.org/centre-for-the-fourth-industrial-revolution/

Yang, L., \& Donahoe, R. J. (2007). The form, distribution and mobility of arsenic in soils contaminated by arsenic trioxide, at sites in southeast USA. Applied Geochemistry, 22(2), 320-341. https://doi. org/10.1016/j.apgeochem.2006.11.005 